\title{
Best strategies to recruit and enroll elderly Blacks into clinical and biomedical research
}

This article was published in the following Dove Press journal:

Clinical Interventions in Aging

\author{
Lennox A Graham' \\ Julius $\mathrm{Ngwa}^{2}$ \\ Oyonumo Ntekim ${ }^{3}$ \\ Oludolapo Ogunlana ${ }^{4}$ \\ Saba Wolday ${ }^{4}$ \\ Steven Johnson ${ }^{3}$ \\ Megan Johnson ${ }^{4}$ \\ Chimene Castor ${ }^{3}$ \\ Thomas $\vee$ Fungwe ${ }^{3}$ \\ Thomas O Obisesan ${ }^{4}$ \\ 'Department of Health Management, \\ College of Nursing and Allied \\ Health Sciences, Howard University, \\ Washington, DC, USA; ${ }^{2}$ Division of \\ Cardiovascular Medicine, College \\ of Medicine, Howard University, \\ Washington, DC, USA; ${ }^{3}$ Department \\ of Nutritional Sciences, College of \\ Nursing and Allied Health Sciences, \\ Howard University, Washington, \\ DC, USA; ${ }^{4}$ Department of Internal \\ Medicine, Howard University Teaching \\ Hospital, Washington, DC, USA
}

Correspondence: Thomas O Obisesan Department of Internal Medicine,

Division of Geriatrics, Department of

Medicine, Howard University Hospital,

204 I Georgia Ave, NW, Washington,

DC 20060, USA

Tel +l 2028658597

Email tobisesan@howard.edu

\begin{abstract}
Background: Historically, Blacks have been disproportionately underrepresented in clinical trials. Outcomes associated with low Blacks' participation in research include poor understanding of the predictors and treatment of the disease, increasing health disparities, poor health equity, and suboptimal wellness of the nation as a whole. To address this gap in research participation, we analyzed our recruitment data to identify the most effective strategies for enrolling older Blacks in clinical trials.
\end{abstract}

Methods: Data used in these analyses were obtained from 3,266 potential volunteers, ages 50 or older, who completed a Mini-Mental State Exam as part of recruitment and screening for various clinical studies on Alzheimer's disease. In order to determine the most effective strategies for engaging Blacks in clinical research, we used tests of proportion to assess significant differences in recruitment sources, counts, and percentages for optimal recruitment strategies by gender. Finally, we employed regression analyses to confirm our findings.

Results: Of the total 3,266 screened, 2,830 Black volunteers were identified for further analysis. Overall, more women than men $(73.8 \%$ vs $26.2 \%)$ participated in our recruitment activities. However, a significantly higher proportion of men than women were engaged through family (3.86\% vs $1.30 \%, p=0.0004)$ and referral sources $(5.89 \%$ vs $2.59 \%, p=0.0005)$. Compared to other sources for recruitment, we encountered a higher proportion of volunteers at health fairs (42.95\%), and through advertisements (14.97\%). In our sample, years of education and age did not appear to influence the likelihood of an encounter, screening, and potential participation.

Conclusion: Our findings indicate Black men and women in our sample were predominantly recruited from health fairs and through advertisements tailored to their health needs and interests. Conversely, we mostly engaged Black men through family referrals and persons known to them, indicating a need for trust in their decision to engage study personnel and/or participate in clinical trials.

Keywords: recruitment strategies, Blacks, screening, community outreach, clinical trials

\section{Background}

One of the most important obstacles to clinical research is the difficulty in recruiting and retaining study participants of all ethnic backgrounds. ${ }^{5,6}$ Historically, Blacks have been disproportionately underrepresented in clinical trials. ${ }^{7-9}$ Although incremental progress has occurred since the establishment of the National Institutes of Health (NIH) Revitalization Act, barriers that influence participation of Blacks in research continue to exist. The NIH has acknowledged the need for increased enrollment of ethnic minorities in biomedical research, yet minority enrollment into clinical and translational research remains low. ${ }^{10}$ Notable contributing factors include negative experiences with the health care system, misunderstandings caused by poor communication, and problems interpreting medical terminology. ${ }^{1-3,7}$ 
Recent data suggest that successful recruitment and enrollment rates have fallen to levels that could endanger the successful completion of some categories of research. ${ }^{10}$ Though overall enrollment into clinical and biomedical research in general continues to be a challenge across multiple studies, minority enrollment poses an even greater challenge. In addition, the elderly, are generally underrepresented. ${ }^{11,12}$ The NIH Revitalization Act of 1993 mandates that grant applicants and cooperative agreement participants include underrepresented minorities in all human subjects' research. Given this awareness, investigators are now more interested than ever in identifying barriers to minority participation in clinical research while concurrently seeking new strategies to overcome known impediments. Mistrust and fear of exploitation and concern about potential harm to self, are notable reasons for the relatively low response rates to recruitment strategies. ${ }^{13}$ Lengthy appointments, parking, repeated phlebotomy, and neuropsychological testing may further compound the challenge posed by mistrust in the recruitment of older Blacks into clinical studies. ${ }^{14}$ Other structural and procedural barriers include lack of public information about clinical trials, limited accessibility, or insurance issues. ${ }^{15-17}$ Moreover, unique researchers attributes can also affect their choice of recruitment strategies. ${ }^{18}$ Two broad types of recruitment strategies have been described, each having distinct and different results. One is the comprehensive approach utilizing a greater number and more diverse and active recruitment strategies; the other is the traditional approach, utilizing fewer and more passive strategies. Jefferson et a ${ }^{19}$ suggested that home visits, provision of transportation, and compensation can motivate volunteers and alleviate some of these barriers.

Because suboptimal minority enrollment into clinical research continues to limit the generalizability of research results, additional mutable determinants of Black participation in clinical research needs more nuanced understanding. To address this gap in knowledge, we examined community engagement and recruitment data at Howard University to identify the most effective methods and strategies that may increase participation of Blacks aged 60 and above in clinical trials on Alzheimer's disease (AD). The overall goal was to inform strategies for future recruitment efforts. The study aims were three-fold: 1) to identify the most effective recruitment strategies for Blacks; 2) to identify recruitment strategies that better engage Blacks compared to other races; and 3) to identify recruitment strategies that provide an optimal environment for one-on-one and group sharing of clinical trial information with older Blacks.

\section{Methods}

\section{Study population and recruitment strategies}

We collected recruitment data consisting of 3,266 potential volunteers from 16 different studies who were aged 50 or older engaged at various recruitment sites. The Howard University Institutional Review Board approved all the studies, including the recruitment materials used for the community engagement activities. In particular, the design and use of deidentified data for the current study were approved by the Howard University Institutional Review Board. In all the studies, volunteers completed a Mini-Mental State Exam (MMSE) as part of screening and recruitment for various clinical studies on AD. The Division of Geriatrics has, over the past 17 years (1999-2016), organized, sponsored, and participated in many health promotion events, such as health fairs and seminars, to educate predominantly the Black community on the warning signs, identification, treatment, and lifestyle changes to reduce the risk of developing $\mathrm{AD}$. Recruitment sites included the geriatric and other medical clinics, church events, health fairs, senior housing and assisted living facilities and senior wellness centers. Additional community engagement activities included: Annual NBC News Expo and Annual Congressional Black Caucus Health Event and Christmas gatherings; engagement of Pastoral Leadership Group; Direct mailing; Newspaper Advertisements (including Senior Beacon, Washington Post, Washington Times, Penny Safer); Metro Bus and Subway Metro Diorama; Hospital and Community-Based Flyers; Hospital Billboard; and Craigslist. Mostly, the study coordinators, our Director of Recruitment, and other members of the study team conducted the presentations and whenever possible, the principal investigator (PI). Volunteers were not compensated for initial engagements and screenings. In order to engage a community or leadership group, first, we established contact through a third party or by sending a letter of introduction by mail. Such initial contact was then followed up with a telephone call. As we became increasingly recognized by the community, we were invited for other community events. Details about the specific recruitment sites and strategies are detailed under outreach.

\section{Community outreach}

The community outreach program included interactions with several organizations at yearly events and at other events that occurred in a less systematic but sporadic basis. During these events, attendees received education on general health concerns common to the geriatric populations, and most 
importantly on memory disorder and neurodegeneration. Often, the PI provided education on currently known risk factors for $\mathrm{AD}$, progress on diagnosis, currently available treatments, and promising preventive strategies. We premised opportunities for prevention mostly on cardiovascular disease risk reduction including lifestyle modification. In addition, the attendees received education on how to differentiate early- from late-onset AD. Each educational session concluded with the provision of emphasis on the importance of clinical trials, a description of enrolling Alzheimer's studies at Howard University Hospital, general inclusion and exclusion criteria, and distribution of educational flyers and brochures on $\mathrm{AD}$. The community outreach arm of the Hospital supported these activities.

\section{Church visits}

As part of the outreach program, we visited over 21 churches each year and created sustained alliances. These alliances occurred mostly in the Howard University geographic region in the District of Columbia and in adjacent Prince George's County, Maryland, that house predominantly Black population. Working in collaboration with these churches, we organized seminars and educated seniors and caregivers on various aspects of health concerns pertaining to the aged: falls, acute delirium, polypharmacy, depression, and, most importantly, memory loss. We implemented a "Lunch and Learn" educational program strategy aimed at encouraging one-on-one interactions with participants.

\section{Health fair programs}

Health fairs are an important component of the overall Howard University community outreach program. The Division of Geriatrics has been a consistent partner and an integral part of the implementation of the outreach program. Collectively, our community outreach team has participated in $\sim 150$ community health fairs in the last 10 years. A significant percentage of participants at these institutional-driven outreach programs came from the entire DELMAVA area (District of Columbia, Maryland, and Virginia) except for Delaware. The programs included general health screenings, engagement of seniors and their caregivers, and education on a variety of geriatrics syndromes including memory loss and $\mathrm{AD}$. We also emphasized the importance of healthy living, brain health, and emerging preventive strategies for $\mathrm{AD}$. The staff encouraged younger volunteers to appreciate the social, psychological, physical, and the economic burden of $\mathrm{AD}$ and encouraged them to disseminate the information received to older family members.

\section{Adult day care and Senior Wellness Centers}

The Washington DC government has over six Senior Wellness Centers where seniors 60 years and older interact and socialize. These centers offer lunch, outings/excursions, computer training, nutrition classes, treadmill exercise, massage, seminars on health issues that affect their groups, and education on medication management, and health, and social services issues. The Howard University community outreach team visited these centers and engaged the attendees through seminars and memory screenings (MMSE) and logical memory when possible. The MMSE and logical memory tests were used to determine inclusion eligibility for each of the $\mathrm{AD}$ clinical trials and diagnostic studies.

\section{Community Alliance for Research Engagement}

This group comprised of church leaders in the Washington DC metropolitan area who met monthly with the PI and our community outreach team to develop best strategies for raising awareness in their respective communities. Educational discussions focused on prevention and treatment of high blood pressure, diabetes, high cholesterol, and memory loss.

\section{Advertisement}

To complement our community outreach activities, and depending on the availability of funds, we periodically advertised through direct mailing, newspaper advertisements (Senior Beacon, Washington Post, Washington Times, Penny Saver, Metro bus and Subway Metro Diorama, hospital and community-based flyers, hospital billboard, and newsletter). Our experience showed that such advertisements yielded optimal results when complemented with a robust community outreach program to maximize its effectiveness. Because of cost constrains, the metro advertisements occured only twice.

\section{Statistical analysis}

Using our recruitment data, we determined the most effective strategies to engage and encourage the enrollment of Blacks in clinical research. All analyses were performed using SAS version 9.3 (SAS Institute, Cary, NC, USA) and Statistical Analysis and Graphics (NCSS 9.0.7, Kaysville, UT, USA).

First, we assessed the data for distribution and the assumption of normality. The baseline descriptive analyses expressed numerical variables as mean and standard deviation, or as the number of participants and percentages when 
categorical. To assess the relationship of recruitment strategies with subjects' engagement and enrollment, we compared continuous variables using the unpaired Student's $t$-test. For the analyses of categorical data, we employed a chi-square test. The unadjusted association assessed each variable for differences in recruitment strategies. A test of proportion was used to discern significant differences in recruitment sources of men compared to women, while percent and counts were computed to determine optimal recruitment strategies separately for men and for women. Boxplots were used to discern the relationships between age and years of education to optimal recruitment strategies, and logistic regression analyses was implemented to compare Blacks with other races in our sample. All $p$-values were obtained two-tailed at statistical significance set at $p<0.05$ and confidence intervals (CI) computed at the $95 \%$ confidence level.

\section{Results}

\section{Characteristics of engaged volunteers}

A total of 3,266 senior residents in the DELMAVA area were engaged as potential volunteers in various research projects. Overall, 86.65\% were Blacks, 15.06\% White, $1.68 \%$ Hispanics, and $1.59 \%$ were Asians (Table 1). Of the total engaged, 49 volunteers self-identified as belonging to other race (mixed race, others, etc). Across races, the sample consisted of a significantly higher percent of women than men (range: $53.6 \%-78.2 \% ; p<0.0001$ ) (Table 1). Similarly, the age distribution of engaged volunteers was similar across racial groups, with mean values ranging between 57 and 62 years. The majority of the participants $(59.5 \%)$ were cognitively normal. Whereas, $36.8 \%$ met criteria for Mild Cognitive Impairment (MCI), 3.8\% met the MMSE criteria for $\mathrm{AD}$ or were previously diagnosed with AD. Whereas, the engaged Whites and Asians volunteers were relatively more educated compared to Blacks and Hispanics, Hispanic volunteers scored lowest on adjusted mean MMSE compared to the others racial groups ( $p=0.069$ ).

From the total 3,266 engaged volunteers, we considered 2,830 Black participants for additional analyses. From this sample, 840 volunteers were excluded either because they were non-Blacks or had missing data about the location/ method of recruitment (Table 2). In general, more women than men (73.9\% vs $26.1 \%)$ participated in all recruitment activities. Overall, the majority of engaged volunteers were recruited through health fairs tailored to their population (42.51\%) and advertisements [(15.28\%) (Figures 1 and 2)], making these the best strategies for engaging and recruiting the population. Overall, a significantly higher percent of Black men compared to women were recruited through family source $(4.13 \%$ vs $1.32 \% ; p=0.0001)$ and referrals (5.89\% vs $2.64 \% ; p=0.0006)$.

We performed logistic regression analysis to assess the relationships between recruitment strategies and race. In the model adjusted for age (at screening), education, and gender differences, Blacks were mostly engaged at churches (odds ratio $[\mathrm{OR}]=7.63 ; \mathrm{CI}: 2.77-21.01)$, health fairs $(\mathrm{OR}=1.84 ; \mathrm{CI}$ : 1.36-2.48), through mass mailing ( $\mathrm{OR}=2.33$; $\mathrm{CI}$ : 1.14-4.76), and at the Wellness Centers (OR $=1.78$; CI: 1.03-3.05) compared to other racial groups (Table 3 ).

\section{Discussion}

The goal of this study was to determine the best recruitment strategies to engage and enroll Blacks in clinical and biomedical research. To achieve this objective, pooled data from 16 studies were analyzed to determine the best recruitment practices for the target population. Overall, our findings indicate that Blacks frequent health fairs and respond to advertisements tailored to their health needs and interests. In addition, successful recruitment occurred when Black men sought the advice of their families and

Table I Demographics and cognitive characteristics of the sample $(\mathrm{N}=3,266)$

\begin{tabular}{|c|c|c|c|c|c|c|}
\hline Characteristics & $\begin{array}{l}\text { All participants } \\
(n=3,266)\end{array}$ & $\begin{array}{l}\text { Blacks } \\
(n=2,830)\end{array}$ & $\begin{array}{l}\text { Whites } \\
(n=280)\end{array}$ & $\begin{array}{l}\text { Hispanics } \\
(n=55)\end{array}$ & $\begin{array}{l}\text { Asians } \\
(n=52)\end{array}$ & $p$-value ${ }^{a}$ \\
\hline Female (\%) & 2,260 (69.20\%) & I,995 (70.49\%) & $150(53.57 \%)$ & 43 (78.18\%) & 33 (63.46\%) & $<0.0001$ \\
\hline Age - yrs & 60.27 (I2.91) & $60.10(12.91)$ & $61.13(12.52)$ & $57.96(15.07)$ & $62.05(12.12)$ & 0.232 \\
\hline \multicolumn{7}{|l|}{ Diagnosis (\%) } \\
\hline Normal & I,549 (59.49\%) & I,298 (58.7I\%) & $156(61.90 \%)$ & 35 (68.63\%) & 27 (6I.36\%) & $<0.0001$ \\
\hline $\mathrm{MCl}$ & 957 (36.75\%) & 846 (38.26\%) & $66(26.19 \%)$ & 15 (29.4 I\%) & 17 (38.64\%) & \\
\hline$A D$ & 98 (3.76\%) & 67 (3.03\%) & 30 (II.90\%) & I (I.96\%) & $0(0.00 \%)$ & \\
\hline Education - yrs & $14.55(3.40)$ & $14.43(3.37)$ & $15.57(3.16)$ & I3.55 (4.38) & $15.40(3.40)$ & $<0.0001$ \\
\hline MMSE & $27.47(5.86)$ & $27.52(6.16)$ & $27.60(3.16)$ & $25.30(4.75)$ & $27.12(2.80)$ & 0.049 \\
\hline Adjusted MMSE & $25.68(4.08)$ & $25.74(4.05)$ & $25.50(4.60)$ & $24.19(4.30)$ & $25.48(2.81)$ & 0.069 \\
\hline
\end{tabular}

Notes: ${ }^{2} 35$ subjects of other race and 14 subjects of mixed race. Data presented as mean ( \pm standard deviation) or $n(\%)$.

Abbreviations: $\mathrm{MCl}$, Mild Cognitive Impairment; AD, Alzheimer's Disease; MMSE, Mini-Mental State Exam. 
Table 2 Characteristics of the sample by recruitment sources

\begin{tabular}{|c|c|c|c|c|}
\hline Recruitment strategy & All participants $\left(n=I, 990^{a}\right)$ & Females $(n=1,439)$ & Males $(n=509)$ & p-value ${ }^{b}$ \\
\hline Advertisement & 304 (I5.28\%) & $215(14.94 \%)$ & $86(16.90 \%)$ & 0.294 \\
\hline Church & I52 (7.64\%) & II 8 (8.20\%) & $33(6.48 \%)$ & 0.213 \\
\hline Family & $40(2.01 \%)$ & $19(1.32 \%)$ & $21(4.13 \%)$ & 0.0001 \\
\hline Friend & $91(4.57 \%)$ & 70 (4.86\%) & $21(4.13 \%)$ & 0.497 \\
\hline Health fair & 846 (42.51\%) & $612(42.53 \%)$ & $200(39.29 \%)$ & 0.203 \\
\hline Mass mailing & $92(4.62 \%)$ & $64(4.45 \%)$ & $28(5.50 \%)$ & 0.336 \\
\hline Newspaper & 207 (10.40\%) & 158 (10.98\%) & $46(9.04 \%)$ & 0.219 \\
\hline Referral & $68(3.42 \%)$ & $38(2.64 \%)$ & $30(5.89 \%)$ & 0.0006 \\
\hline Wellness center & 169 (8.49\%) & I 30 (9.03\%) & 38 (7.47\%) & 0.279 \\
\hline
\end{tabular}

Notes: a840 Subjects with missing recruitment category; 42 subjects with missing gender; btest of proportion to obtain $p$-values. Data presented as $n$ (\%).

friends while considering participation in clinical studies. Complementing these strategies with radio advertisements, emails, flyers, newspapers, health fairs, and direct mailing can further bolster recruitment. Collectively, effective minority recruitment into clinical trials requires the same amount of resources and attention devoted to research design and data analysis. $^{20}$

The reluctance of Blacks to participate in clinical research is rooted in apprehension for the system and its historical perspective dating back to the Tuskegee Study. ${ }^{15,21,22}$ Such historic abuses of research participants, as well as news reports of the unethical motivation of some clinical investigators, has contributed to the mistrust among the public in general and among minority populations in particular..$^{23,24}$ Unfortunately, progress on improving recruitment of ethnic

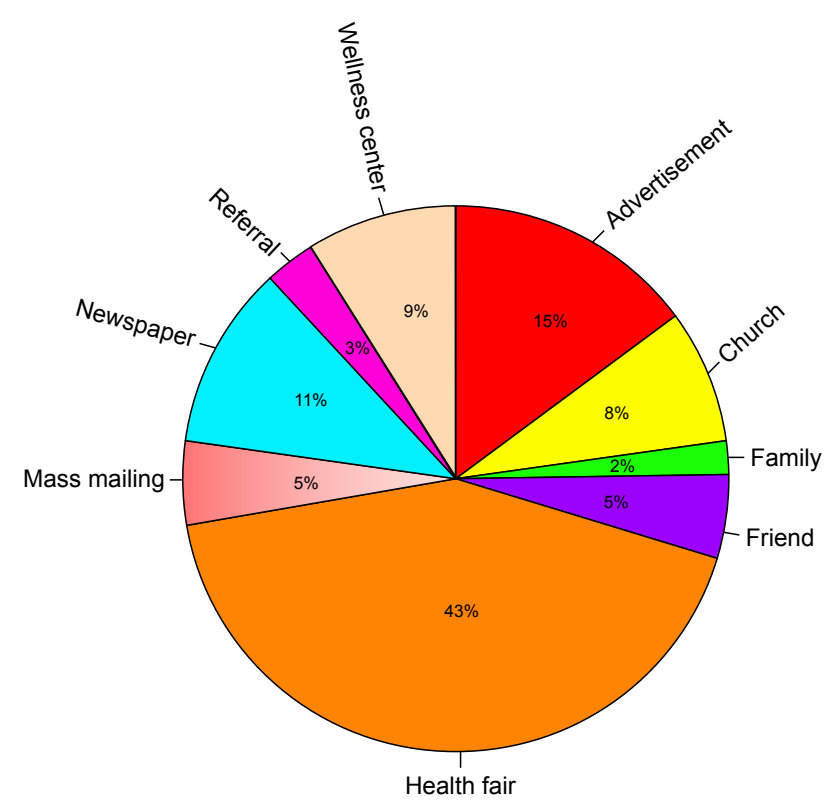

Pie chart of recruitment strategies

Figure I Pie chart showing the overall relative distribution of strategies used to engage the community in the sample. minorities has been slow, with consequent widening of health disparities and lack of health equity. Nonetheless, a well-planned strategy is likely to minimize the challenges of recruitment and retention. While some approaches to recruitment may have traditionally relied upon mailing advertisements, telephone solicitation, recruitment within traditional settings (eg, hospitals/clinics), or public databases/ registries, our findings at health fairs and seminars are in agreement with Dreer et $\mathrm{al}^{25}$ that a more interactive approach is likely to further enhance recruitment outcomes, especially in underserved minority populations.

In the current study, we observed that higher percent of our Black sample were women. This observation is in agreement with the view that women are generally more likely to participate in clinical and translational studies. ${ }^{26}$ Particularly, African American (AA) women are motivated to participate in health-related research because of altruism, monetary, and other compensations, but may be discouraged by the need for change in one's daily routine. ${ }^{27,28}$ However, active community engagement by a dedicated research team, use of existing networks for advertisement, and the relevance of the study to the health needs of the population have all been observed to increase trust, and therefore, increased participation of Black women in clinical research. ${ }^{29,30}$ For example, the successful use of established social networks such as churches and community centers to recruit AA women into a breast cancer genetic counseling program is in concordance with previously published observations. ${ }^{31}$ Therefore, our observation of heightened engagement of AA women through churches and community centers add credence to the current body of evidence in the literature.

Whereas many of the currently employed strategies may be applicable to several racial groups, successful implementation of other strategies are likely predicated upon the educational level and age of the population of interest. Our observation of increased engagement of Black men through 


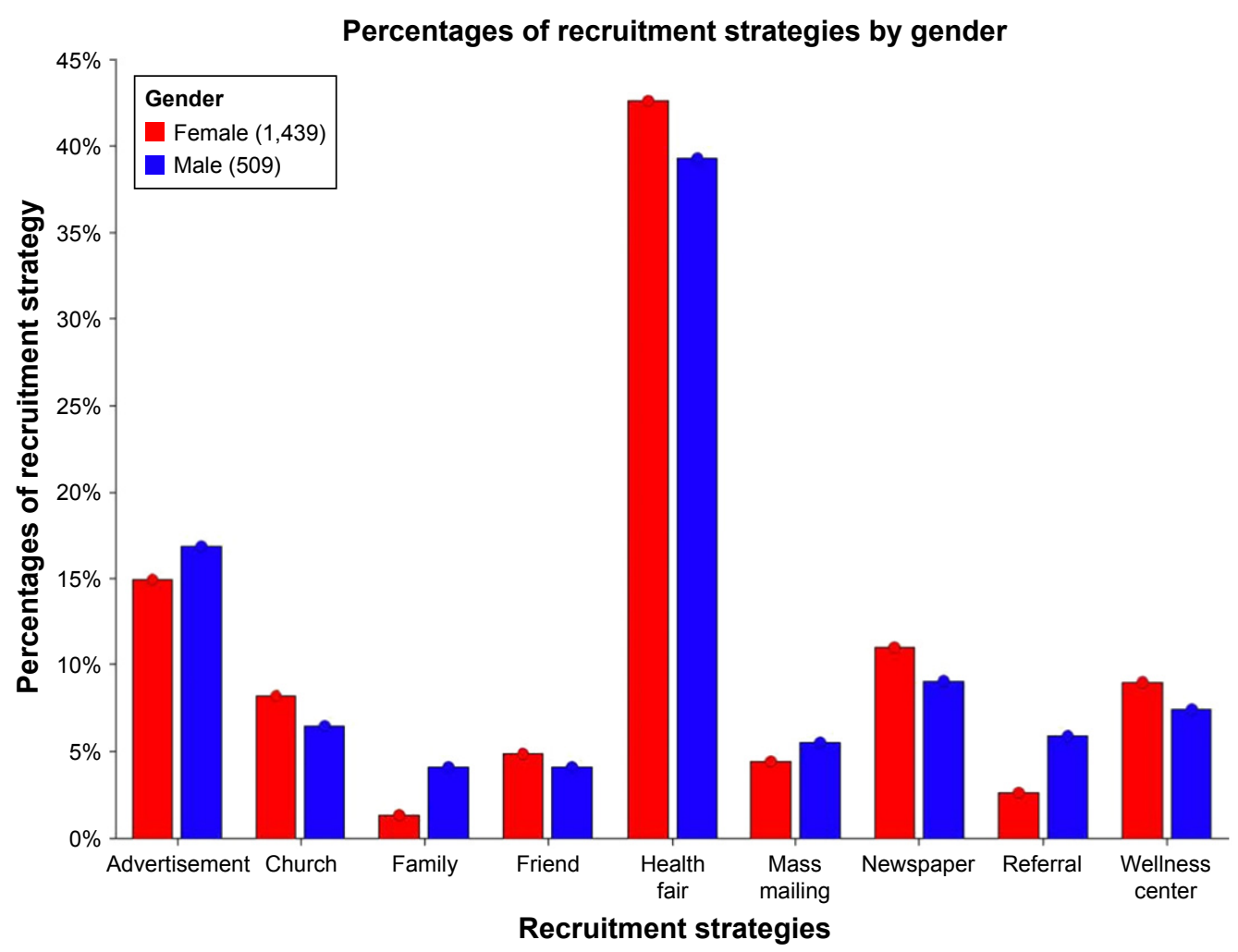

Figure 2 Gender-based distribution of strategies used to engage the community in the sample.

family referral sources is a new and important addition to the literature. Several strategies have been previously employed, but with limited success. In one study, distributing flyers to community clinics, physician offices, churches, and barbershops serving older Black men failed to increase enrollment. This suggests that other strategies must be employed. ${ }^{32}$ However, an alternative approach that employed the concept of a trusted source included $\sim 1,003$ Black churches, each setting a recruitment goal based on church attendance. Serving as recruiters, a pastor and a church member shared study information with the congregation and received monetary

Table 3 Logistic regression analysis of the relationships of race to recruitment strategies among Blacks vs others

\begin{tabular}{llll}
\hline Characteristics & OR & \multicolumn{2}{l}{$\begin{array}{l}\text { 95\% Confidence } \\
\text { Interval }\end{array}$} \\
\hline Age at screening & 1.001 & 0.990 & 1.012 \\
Education & 0.960 & 0.924 & 0.998 \\
Gender & 0.751 & 0.565 & 0.999 \\
Church & 7.625 & 2.767 & 21.010 \\
Health fair & 1.837 & 1.360 & 2.480 \\
Mass mailing & 2.330 & 1.141 & 4.759 \\
Wellness center & 1.775 & 1.034 & 3.047 \\
\hline
\end{tabular}

Notes: Logistic regression analysis comparing recruitment strategies among "Blacks" vs other race; Stepwise regression model adjusting for age at screening, education, and gender (male vs female).

Abbreviations: $\mathrm{Cl}$, confidence interval; $\mathrm{OR}$, odds ratio. incentives upon returning the questionnaires. ${ }^{33}$ Another trusted source approach used the snowball recruitment strategy, where eligible volunteers recruited others with similarly suitable characteristics, and then continued in a fashion analogous to a snowball effect. ${ }^{34}$ This array of trustrelated strategies may be best suited for recruiting Blacks into clinical trials, and particularly relevant for studies on diseases plagued by stigma such as $\mathrm{AD}$.

\section{Conclusion}

Collectively, elderly Blacks are more likely to respond to health fairs and targeted advertisements for clinical trials. Our results indicate that churches, health fairs, mass mailings, and wellness centers may be better suited for the recruitment of Blacks into clinical and biomedical research. These techniques were implemented as part of the multiple sustained relationships with the black community. A well thought out and scientifically proven strategy, informed by characteristics of the target population may bolster enrollment. While Black men may depend more on family referrals when considering participation in clinical research, health fairs may provide an environment for one-on-one and group sharing of clinical trials information with older Blacks in general. More studies should consider qualitative research to elucidate 
factors influencing the participation of Blacks in clinical studies. A limitation of this study is the use of secondary data restricted to existing variables in our sample. Nonetheless, the use of a relatively large predominantly Black population and the generation of new insight into the best strategies for engaging and recruiting Blacks into clinical and biomedical research make this contribution unique.

\section{Acknowledgment}

This work was supported by the National Institute on Aging at the NIH grant R01 5R01AG31517, 5R01AG045058 to Obisesan TO; and in part by Grant \#UL1TR000101 from National Center for Advancing Translational Sciences/ NIH through the Clinical and Translational Science Award Program (CTSA). The Howard University Institutional Review Board approved this study and analyses. All participants enrolled in relevant studies provided written informed consent. An abstract of this research was presented as a supplement in Alzheimer's and Dementia, July 2015, Volume 11, Issue 7, Supplement, Pages P575-P576.

\section{Author contribution}

LG, JN, TVF, and TOO participated in the design of the study and performed the statistical analysis. ON, OO, SW, SJ, MJ, $\mathrm{CC}, \mathrm{LG}, \mathrm{JN}, \mathrm{TVF}$, and TOO conceived the study participated in its design and coordination. All authors contributed toward data analysis, drafting and critically revising the paper and agree to be accountable for all aspects of the work.

\section{Disclosure}

The authors report no conflicts of interest in this work.

\section{References}

1. Aycinena AC, Valdovinos $\mathrm{C}$, Crew KD, et al. Barriers to recruitment and adherence in a randomized controlled diet and exercise weight loss intervention among minority breast cancer survivors. J Immigr Minor Health. 2017;19(1):120-129.

2. Durant RW, Wenzel JA, Scarinci IC, et al. Perspectives on barriers and facilitators to minority recruitment for clinical trials among cancer center leaders, investigators, research staff, and referring clinicians: enhancing minority participation in clinical trials (EMPaCT). Cancer. 2014;120(Suppl 7):1097-1105.

3. Newman PA, Duan N, Roberts KJ, et al. HIV vaccine trial participation among ethnic minority communities: barriers, motivators, and implications for recruitment. J Acquir Immune Defic Syndr. 2006;41(2): 210-217.

4. Tombaugh TN, McIntyre NJ. The mini-mental state examination: a comprehensive review. J Am Geriatr Soc. 1992;40(9):922-935.

5. Napoles A, Cook E, Ginossar T, Knight KD, Ford ME. Applying a conceptual framework to maximize the participation of diverse populations in cancer clinical trials. Adv Cancer Res. 2017;133:77-94.

6. Heller C, Balls-Berry JE, Nery JD, et al. Strategies addressing barriers to clinical trial enrollment of underrepresented populations: a systematic review. Contemp Clin Trials. 2014;39(2):169-182.
7. Hamel LM, Penner LA, Albrecht TL, Heath E, Gwede CK, Eggly S. Barriers to clinical trial enrollment in racial and ethnic minority patients with cancer. Cancer Control. 2016;23(4):327-337.

8. Castillo-Mancilla JR, Cohn SE, Krishnan S, et al. Minorities remain underrepresented in HIV/AIDS research despite access to clinical trials. HIV Clin Trials. 2014;15(1):14-26.

9. Adams-Campbell LL, Ahaghotu C, Gaskins M, et al. Enrollment of African Americans onto clinical treatment trials: study design barriers. J Clin Oncol. 2004;22(4):730-734.

10. Bryant K, Wicks MN, Willis N. Recruitment of older African American males for depression research: lessons learned. Arch Psychiatr Nurs. 2014;28(1):17-20.

11. Emanuel EJ, Wendler D, Grady C. What makes clinical research ethical? JAMA. 2000;283(20):2701-2711.

12. Rochon PA, Berger PB, Gordon M. The evolution of clinical trials: inclusion and representation. CMAJ. 1998;159(11):1373-1374.

13. Braunstein JB, Sherber NS, Schulman SP, Ding EL, Powe NR. Race, medical researcher distrust, perceived harm, and willingness to participate in cardiovascular prevention trials. Medicine (Baltimore). 2008; 87(1):1-9.

14. Marcantonio ER, Aneja J, Jones RN, et al. Maximizing clinical research participation in vulnerable older persons: identification of barriers and motivators. J Am Geriatr Soc. 2008;56(8):1522-1527.

15. Giuliano AR, Mokuau N, Hughes C, et al. Participation of minorities in cancer research: the influence of structural, cultural, and linguistic factors. Ann Epidemiol. 2000;10(Suppl 8):S22-S34.

16. Bruner DW, Jones M, Buchanan D, Russo J. Reducing cancer disparities for minorities: a multidisciplinary research agenda to improve patient access to health systems, clinical trials, and effective cancer therapy. J Clin Oncol. 2006;24(14):2209-2215.

17. Lara PN Jr, Higdon R, Lim N, et al. Prospective evaluation of cancer clinical trial accrual patterns: identifying potential barriers to enrollment. J Clin Oncol. 2001;19(6):1728-1733.

18. Quinn SC, Butler J 3rd, Fryer CS, et al. Attributes of researchers and their strategies to recruit minority populations: results of a national survey. Contemp Clin Trials. 2012;33(6):1231-1237.

19. Jefferson AL, Lambe S, Chaisson C, Palmisano J, Horvath KJ, Karlawish J. Clinical research participation among aging adults enrolled in an Alzheimer's Disease Center research registry. J Alzheimers Dis. 2011;23(3):443-452.

20. Dancy BL, Wilbur J, Talashek M, Bonner G, Barnes-Boyd C. Community-based research: barriers to recruitment of African Americans. Nurs Outlook. 2004;52(5):234-240.

21. Lang R, Kelkar VA, Byrd JR, Edwards CL, Pericak-Vance M, Byrd GS. African American participation in health-related research studies: indicators for effective recruitment. J Public Health Manag Pract. 2013;19(2):110-118.

22. Sateren WB, Trimble EL, Abrams J, et al. How sociodemographics, presence of oncology specialists, and hospital cancer programs affect accrual to cancer treatment trials. J Clin Oncol. 2002;20(8): 2109-2117.

23. Kelch RP. Maintaining the public trust in clinical research. $N$ Engl J Med. 2002;346(4):285-287.

24. Cohen GI. Clinical research by community oncologists. $C A$ Cancer J Clin. 2003;53(2):73-81.

25. Dreer LE, Weston J, Owsley C. Strategic planning for recruitment and retention of Older African Americans in health promotion research programs. J Health Dispar Res Pract. 2014;7(2):14-33.

26. Covell NH, Frisman LK, Essock SM. Rates of refusal to participate in research studies among men and women. Psychiatr Serv. 2003;54(11): 1541-1544.

27. Neill KM, Chessa F. Recruitment and retention of women in nontherapeutic clinical trials. Appl Nurs Res. 1998;11(3):148-151.

28. Merton V. The exclusion of pregnant, pregnable, and once-pregnable people (a.k.a. women) from biomedical research. Am J Law Med. 1993; 19(4):369-451. 
29. Rogers JL, Johnson TR, Brown MB, Lantz PM, Greene A, Smith YR. Recruitment of women research participants: the Women's Health Registry at the University of Michigan. J Womens Health (Larchmt). 2007;16(5):721-728.

30. Smith YR, Johnson AM, Newman LA, Greene A, Johnson TR, Rogers JL. Perceptions of clinical research participation among African American women. J Womens Health (Larchmt). 2007;16(3):423-428.

31. Patterson A, Davis H, Euhus D, Neuhausen S, Strong L, Tomlinson G. Recruitment for breast cancer predisposition studies in an underserved African American population. Breast J. 2005;11(1):79-82.
32. Bryant K, Moore T, Willis N, Hadden K. Development of a faithbased stress management intervention in a rural African American Community. Prog Community Health Partnersh. 2015;9(3):423-430.

33. Herring P, Butler T, Hall S, Bennett H, Montgomery SB, Fraser G. Recruiting and motivating black subjects to complete a lengthy survey in a large cohort study: an exploration of different strategies. BMC Med Res Methodol. 2014;14:46.

34. Sadler GR, Lee HC, Lim RS, Fullerton J. Recruitment of hard-to-reach population subgroups via adaptations of the snowball sampling strategy. Nurs Health Sci. 2010;12(3):369-374.

\section{Publish your work in this journal}

Clinical Interventions in Aging is an international, peer-reviewed journal focusing on evidence-based reports on the value or lack thereof of treatments intended to prevent or delay the onset of maladaptive correlates of aging in human beings. This journal is indexed on PubMed Central, MedLine,

\section{Dovepress}

CAS, Scopus and the Elsevier Bibliographic databases. The manuscript management system is completely online and includes a very quick and fair peer-review system, which is all easy to use. Visit http://www.dovepress. com/testimonials.php to read real quotes from published authors. 